\title{
Similarities and Differences between Children with Asthma wnd Children with Cancer: Implications for Preventive Intervention
}

\author{
Kristine Siefert, Ph.D., MPH, ${ }^{1}$ Daniela Wittmann, MSW, ACSW, ${ }^{2}$ \\ Susan Farquar, MSW, ${ }^{3}$ and Frances Talsma, MSW $^{3}$
}

\begin{abstract}
A substantial increase in the prevalence of chronic health conditions among children in the U.S. has led to growing concern with preventing the psychosocial and economic problems engendered by such illness. This exploratory study examined the validity of the recently proposed non-categorical approach to physical illness versus the traditional disease-specific perspective as the basis for the content and organization of preventive services for children with chronic illness. No significant disease-specific differences were found in measures of psychological and social adaptation between children with asthma and children with cancer, lending support to a non-categorical approach to the provision of preventive services.
\end{abstract}

KEY WORDS: chronic illness; child health services; social adjustment.

Over the past several decades, the number of children with chronic illness has increased substantially. It is conservatively estimated that 10 to 20 percent of U.S. children have a chronic health condition, and approximately one million of these children are afflicted with severe chronic illness (Perrin and MacLean, 1988; Hobbs, Perrin and Ireys, 1985). Between 1969 and 1981, the prevalence of activity-limiting and chronic conditions among children under 17 increased 44 percent (Newacheck, Budetti and Halfon,

\footnotetext{
${ }^{1}$ Kristine Siefert is Associate Professor, School of Social Work, University of Michigan, Ann Arbor, MI 48109-1285.

${ }^{2}$ Frances Talsma is Clinical Social Worker, Mott Children's Hospital, University of Michigan Medical Center.

${ }^{3}$ Susan Farquar and Daniela Wittmann were Clinical Social Workers, Pediatric Pulmonary and Pediatric Oncology Clinics, University of Michigan Medical Center at the time of this study.
} 
1986). Although some of this increase is attributable to changes in methodology and reporting, much of it represents improved survival of children with chronic illness. The survival rate to adulthood of children with longterm severe chronic illness is currently approximately 80 percent (Gortmaker, 1985). Basic biomedical research has led to major advances in medical care, which has in turn increased longevity among children who previously would have died.

At the same time that advances in medical technology have led to improved survival of children with chronic illness, issues of quality of life for these children and their families have been relatively neglected (Hobbs and Perrin, 1985). There is substantial empirical evidence that children with chronic illness and their families are at increased risk of mental health problems (Stein, 1989), and the need for increased attention to preventive intervention on their behalf has been noted (Silverman and Koretz, 1989). In addition, families of children with chronic illness often face difficulty in obtaining support for the special educational, social, and financial needs engendered by such illness (Pless and Perrin, 1985). Moreover, health care providers tend to view chronic illness in terms of discrete disease entities (Stein and Jessop, 1984). Thus, studies of the psychosocial impact of chronic illness typically focus on a specific diagnosis, and tend to view the psychosocial problems associated with each disease as unique. Typically, patients with a specific illness are compared with normal populations, or with subgroups within the same diagnostic category (Cassileth et al., 1984). The result is a disease-specific concept of psychosocial response to chronic illness, and even disease-specific personality profiles. Children with asthma, for example, have been described variously as suppressing their emotions, as having an intrinsic "panic trait," or as being dependent, hostile, or depressed (Meijer, 1979; Dirks, Paley, and Fross, 1979). Parents of children with asthma have been described as overprotective, intrusive, rejecting, or unmotivated and indifferent (Staudenmayer, 1981; Zlatich, 1982).

Even when environmental and contextual variables are addressed in research, the body of work that accumulates around a specific disease entity tends to exist in isolation from information about children with other chronic illnesses (Cassileth et al., 1984). Thus, little is known about how children with cancer differ from children with diabetes or children with cystic fibrosis, although such information could be useful for families of children with other chronic conditions (Stein and Jessop, 1984). Differences in adjustment and need for services are not necessarily disease-specific, although services for children with chronic illness are organized around disease categories. In addition, the use of diagnostic labels-e.g., "diabetic"-stereotypes and stigmatizes children, and fails to describe the health of the child as a whole. 


\section{A NON-CATEGORICAL PERSPECTIVE}

In a major departure from the categorical, or disease-by-disease approach to research and service delivery for children with chronic diseases, researchers have recently begun to recognize that issues such as social and psychological adjustment and impact on the family are common to a variety of diseases (Pless and Perrin, 1985). In a groundbreaking study, Stein and Jessop $(1982,1984)$ examined a number of child and family indicators, including the child's social and psychological adjustment; family functioning; social support of the mother; and the child's general health status among children with asthma, myelomeningocele, multiple handicaps, and hemoglobinopathies. No significant differences in any of the measures could be accounted for by the child's diagnosis. More within-group than betweengroup variation was found; the only significance difference among the groups studied was the physician's assessment of the overall burden to the family in caring for the child. This suggests that regardless of the diagnosis, chronic illness has a similar impact on the child and the family, and that any dysfunction that occurs is the result of chronicity itself, rather than a specific disease (Perrin and MacLean, 1984).

If Stein and Jessop's findings are supported by other research, there are major implications for service delivery. If risk of dysfunction is not disease-specific, other factors must be considered in assessing vulnerability and allocating resources. The shift from hospital to community and family-based care resulting from changes in health care financing, combined with decreasing resources for ancillary services resulting form cost-containment measures over the past decade, are placing an increased burden on the family as the provider of care. Past experience has shown that when funds are scarce, other services shrink (Hutchins, 1984). As Starfield (1985) notes, researchers involved in children's ambulatory care have not adequately addressed this issue, and as states increasingly adopt reimbursement schemes based on cases rather than services and on prospective payment rather than fee-for-service, it is imperative that research provide the data that make the process rational.

This exploratory study addresses the following question: are there any disease-specific differences in the social and psychological adjustment of the child or impact on the family among children with two very different disease entities: children with asthma, and children with cancer. The traditional view suggests that the impact of asthma and the impact of cancer on the child and family should differ considerably: asthma is generally a chronic, but non-fatal disorder, while cancer is catastrophic, dreaded, and life-threatening (Siegel, 1980). If the categorical approach proposed by Stein and Jessop $(1982,1984)$ is valid, there should be no significant dif- 
ferences in psychosocial status and family functioning among children and families in the two diagnostic groups.

\section{SAMPLE AND METHOD}

To investigate the hypothesis that there are no significant differences in social and psychological adjustment and family functioning between children with asthma and children with cancer, an exploratory study was undertaken in a large midwestern university medical center. Funding was provided through the preliminary research small grants programs of the American Cancer Society and the National Institutes of Health. A crosssectional survey design was used. Subjects of the study were children aged four to twelve who had been given a primary medical diagnosis of cancer or asthma and who were patients in the Pediatric Hematology or Asthma clinics of the Division of Ambulatory Care. Only children whose treatment included chemotherapy were included in the study group so as to properly represent the chronicity of the illness. One key family member for each patient was surveyed: the patient's mother or father, or whoever was identified as the child's primary source of care living at home. Families were invited to voluntarily participate and consent from both the child and the parent was obtained.

Twenty subjects were randomly selected from the case loads of each clinic. None of the parents or children refused to participate. Table 1 presents the demographic characteristics of the sample. There were no significant differences between children in the two diagnostic groups with respect to age, sex, race, parents' marital status, and parents' education, but the children with asthma had a significantly greater length of time since diagnosis $(p=.002)$ and significantly higher household income $(p=.02)$ than the children with cancer. The variance for household income of children with asthma was nearly six times that of children with cancer, however, making the mean differences less informative.

Parents were interviewed in the clinics using a structured questionnaire that included several self-administered instruments. In addition, trained nursing staff in the Pediatric Oncology and Asthma clinics were asked to complete a clinical assessment of caregiver burden for each child, and trained medical, nursing or social work staff rated each child for the presence or absence of depression. Supplementary sociodemographic and medical data were collected from the medical record by project staff. 
Table 1. Demographic Characteristics of Sample

\begin{tabular}{|c|c|c|}
\hline & Asthma $(\mathrm{N}=20)$ & Cancer $(\mathrm{N}=20)$ \\
\hline Age (yr) & 9.2 & 7.8 \\
\hline Range & $(4-13)$ & $(4-13)$ \\
\hline \multicolumn{3}{|l|}{ Sex, \% } \\
\hline $\mathrm{F}$ & 45.0 & 20.0 \\
\hline $\mathbf{M}$ & 55.0 & 80.0 \\
\hline \multicolumn{3}{|l|}{ Race, \% } \\
\hline Black & 5.0 & \\
\hline Latino & & 5.0 \\
\hline White & 95.0 & 95.0 \\
\hline Years Since Diagnosis* & 5.5 & 2.2 \\
\hline \multicolumn{3}{|l|}{ Parents' Marital Status, $\%$} \\
\hline Married & 95.0 & 80.0 \\
\hline Divorced & 5.0 & 20.0 \\
\hline \multicolumn{3}{|l|}{ Mother's Education, \% } \\
\hline Grade School & - & 5.0 \\
\hline Some High School & 15.0 & 20.0 \\
\hline High School Graduate & 25.0 & 50.0 \\
\hline Technical/Business School & 10.0 & - \\
\hline Some College & 25.0 & 15.0 \\
\hline College Graduate & 10.0 & 5.0 \\
\hline \multicolumn{3}{|l|}{ Professional Degree or } \\
\hline Post-College Degree & 15,0 & 5.0 \\
\hline \multicolumn{3}{|l|}{ Father's Education, \% } \\
\hline Grade School & 2.5 & 5.0 \\
\hline Some High School & 17.5 & 20.0 \\
\hline High School Graduate & 25.0 & 30.0 \\
\hline Technical/Business School & 10.0 & 10.0 \\
\hline Some College & 20.0 & 25.0 \\
\hline College Graduate & 12.5 & 10.0 \\
\hline \multicolumn{3}{|l|}{ Professional Degree or } \\
\hline Post-College Degree & 12.5 & \\
\hline Household Income** & $\$ 35,930$ & $\$ 20,940$ \\
\hline S.D. & 24,328 & 10,245 \\
\hline
\end{tabular}

${ }^{*} \mathrm{~F}=11.18, \mathrm{p}=.002$.

${ }^{* *} \mathrm{~F}=6.45, \mathrm{p}=.02$.

\section{MEASURES}

Children's psychological adaptation and social functioning were measured using the following instruments: the Childhood Depression Rating Scale (Poznanski et al., 1979; Poznanski, 1984); the Interpersonal Functioning subscale of the Functional Status Measure (Stein and Jessop, 1982); and the Behavior Problems Scale of the Child Behavior Checklist (Achenbach and Edelbrock, 1983). 
The Childhood Depression Rating Scale (Poznanski et al., 1979; Poznanski, 1984) is a well-established measure of the severity as well as the presence of depressed mood in children. Concurrent validity has been established, and a high degree of correlation $(r=.96)$ has been found between its average summary score and independent ratings by child psychiatrists. Raters were trained in the use of the scale until inter-rater reliabilities reached an acceptable level prior to its use in the present study. The Interpersonal Functioning Scale of the Functional Status Measure (Stein and Jessop, 1982), measures the behavioral consequences of disease for the social functioning of the child. It includes leisure, work, and rest activities and assesses age-appropriate behavior in the home, the school, and the neighborhood. It is designed to differentiate among chronically ill children and has a Chronbach alpha coefficient of 0.72. The Child Behavior Checklist (CBCL) is an empirically derived questionnaire consisting of a child-behavior profile which contains behavior problem scales. It has excellent psychometric properties, and has been widely used in research on children with chronic illness (Pless, 1984). A profile is generated from 113 items completed by the parent, and a standardized summary behavior-problem T-score is generated. A T-score greater than 63 classifies a child as dysfunctional. However, it is designed in such a way that the diagnostic meaning of changes below a specific cut-off point is unclear, and since the focus of this study is differences and similarities among chronically ill children rather than a comparison of such children with the general population, only the raw scores were used in the present analysis.

Family functioning and social support were measured by having parents complete the Social Health Battery (Brook, Ware, Davies-Avery, et al., 1979) and the Family Assessment Device (FAD) (Miller et al., 1985). Both are well established measures with a high degree of reliability and validity. The General Functioning subscale of the FAD was used for this analysis; this scale assesses the overall health of the family and has a Chronbach's alpha of .92 (Epstein, Baldwin, and Bishop, 1983).

The overall burden to the family in caring for the child was measured by specially trained nurses' ratings on the Clinician's Overall Burden Index (COBI) (Stein and Jessop, 1984). The COBI measures generic features of illness including medical and nursing tasks required of the parents, disruption in family routine, fixed deficits in the child that place demands on the parents, dependence of the child, and psychological burden. It has demonstrated high criterion-oriented validity $(\mathrm{r}=.82, \mathrm{p}=.001)$. Parents also rated burden and the child's general health status using the Parent Burden and General Functioning subscales of the Functional Status Measure (Stein and Jessop, 1982). Both have demonstrated high reliability (alpha $=.72$ ) 
and the general health factor discriminates significantly between well and ill children $(p=0.0001)$.

\section{FINDINGS}

Mean scores on the three measures of child psychological and social adaptation and on the measure of family functioning were compared for the two groups. Table 2 presents the results. No significant differences between children with asthma and children with cancer were found in levels of depression, interpersonal functioning, behavior problems, or family functioning. Mean scores on the measures of physical functioning and severity of burden imposed by the child's illness were then compared; interestingly, nurses rated children with asthma as imposing a significantly higher overall burden on their parents than children with cancer (Table 3). Parents of children with cancer, however, perceived a significantly higher level of burden than parents of children with asthma. There were no significant differences in parents' ratings of their child's general health between the two groups. Zero-order correlations were than computed between demographic and illness-related characteristics and the four measures of child and family adaptation (Table 4). Higher income was significantly associated with higher levels of family functioning, and there was an inverse relationship between higher perceived burden on the part of the parents and lower levels of family functioning. There were no significant correlations between length of time since diagnosis and any of the outcome measures. Nurses' ratings of the overall burden imposed on the parents by the child's illness was significantly associated with higher levels of child depression, and higher parent ratings of the child's general health were significantly correlated with higher levels of interpersonal functioning and lower levels of behavior problems

\section{DISCUSSION}

Conducting research with children with serious illness is a labor-intensive undertaking, and the constraints of time, limited funding, and the exploratory nature of this study precluded the enrollment of a larger number of subjects at this time. Thus, serious consideration must be given to the possibility of a type II error, and the study must be replicated on a sample large enough to insure sufficient statistical power to reject the null hypothesis before definitive conclusions can be made (Cohen, 1977; Cohen and Cohen, 1983). Nevertheless, the findings do lend support for the ar- 
Table 2. Comparisons between Children with Asthma and Children with Cancer on Measures of Psychological, Social, and Family Adaptation

\begin{tabular}{lcccc}
\hline \multicolumn{1}{c}{ Measure } & Asthma & Cancer & F & P \\
\hline Depression & & & & \\
M & 27.80 & 26.11 & .284 & ns \\
SD & 11.45 & 8.01 & & \\
Interpersonal & & & & \\
Functioning & & & & \\
M & 36.35 & 35.25 & .698 & ns \\
SD & 2.78 & 5.19 & & \\
Behavior & & & & \\
Problems & 147.40 & 146.90 & .696 & ns \\
M & 15.63 & 21.79 & & \\
SD & & & & \\
Family & & & & \\
Functioning & 38.75 & 37.05 & .975 & ns \\
M & 6.0 & 4.83 & & \\
SD & & &
\end{tabular}

gument that there are no disease-specific differences in the social and psychological adjustment of children with chronic illness. While the limitations imposed by a small, voluntary sample in which single parents and ethnic minorities are underrepresented must be kept in mind, the relative homogeneity of the sample increases its internal validity. If replicated on other

Table 3. Children's Status on Measures of Physical Functioning and Severity of Burden Imposed by Illness

\begin{tabular}{lrrrr}
\hline \multicolumn{1}{c}{ Measure } & Asthma & Cancer & F & P \\
\hline Clinician's Overall & & & & \\
Burden Index ** & & & & \\
M & 201.75 & 116.45 & 31.85 & .0000 \\
SD & 49.70 & 45.82 & & \\
Parent Assessment & & & & \\
of Burden* & 141.90 & 160.10 & 4.75 & .0355 \\
M & 24.64 & 28.05 & & \\
SD & & & & \\
Parent Assessment & & & & \\
of Child's General & & & \\
Health & 47.75 & 47.90 & .161 & ns \\
M & 3.49 & 3.96 & & \\
SD & & & & \\
\hline *p $<.05$ & & & & \\
$*$ * p $<.001$ & & &
\end{tabular}


Table 4. Zero-Order Correlations between Demographic and Illness-Related Factors and Child and Family Adaptation Measures

\begin{tabular}{lcccc}
\hline \multicolumn{1}{c}{ Factor } & Depression & $\begin{array}{c}\text { Interpersonal } \\
\text { Functioning }\end{array}$ & $\begin{array}{c}\text { Behavior } \\
\text { Problems }\end{array}$ & $\begin{array}{c}\text { Family } \\
\text { Functioning }\end{array}$ \\
\hline Income & .092 & .040 & -.054 & $.483^{* *}$ \\
Years Since & $\mathrm{ns}$ & $\mathrm{ns}$ & $\mathrm{ns}$ & $\mathrm{p}=.002$ \\
$\begin{array}{l}\text { Diagnosis } \\
\text { Clinician's Overall }\end{array}$ & .136 & .124 & .115 & -.103 \\
Burden Index & $\mathrm{ns}$ & $\mathrm{ns}$ & $\mathrm{ns}$ & $\mathrm{ns}$ \\
& $.339^{*}$ & .047 & .084 & -.109 \\
$\begin{array}{l}\text { Parent Assessment } \\
\text { of Burden }\end{array}$ & $\mathrm{p}=.035$ & $\mathrm{~ns}$ & $\mathrm{~ns}$ & $\mathrm{~ns}$ \\
& .298 & -.160 & .245 & $-.405^{*}$ \\
$\begin{array}{l}\text { Parent Assessment } \\
\text { of General Health }\end{array}$ & $\mathrm{ns}$ & $\mathrm{ns}$ & $\mathrm{ns}$ & $\mathrm{p}=.010$ \\
& -.2118 & $.563^{* * *}$ & $-.370^{*}$ & -.083 \\
& $\mathrm{~ns}$ & $\mathrm{p}=.000$ & $\mathrm{p}=0.19$ & $\mathrm{~ns}$ \\
\hline
\end{tabular}

\footnotetext{
${ }^{*} \mathrm{p}<.05$

${ }^{* *} \mathrm{p}<.01$

$* * * \mathrm{p}<.001$
}

populations, the findings reported here have implications for the provision of services to children with chronic illness. If medical diagnosis is not a determinant of psychological and social adaptation, the organization of services for children and families by disease category does not make sense. The findings of this study, if validated by further research, suggest that families would be better served by the generic provision of services across disease categories, rather than having to rely on the resources allocated to a particular disease.

Silverman and Koretz (1989) note that a noncategorical view of physical illness parallels the paradigmatic shift from a search for predisposing to precipitating factors with respect to psychological disorders proposed by Bloom (1979). Both perspectives view children with chronic illness and their families as being at risk due to exposure to stressful situations, independent of a specific physical disorder (Silverman and Koretz, 1989). This implies the need to develop and test and refine an array of preventive interventions to reduce the stress engendered by chronic illness. Such interventions can target the child, the family, or the environment, depending on the specific risk factors present.

The finding of a significant relationship between lower income and lower levels of family functioning suggests that poor families may be particularly vulnerable to stress and may benefit considerably from preventive 
intervention, including economic supports to offset the considerable cost engendered by chronic physical illness.

Finally, the difference between parents' and nurses' ratings of burden imposed by the child's illness and the relationship between higher levels of perceived burden on the part of the parents and lower levels of family functioning raise a number of issues and questions related to the accuracy of staff perceptions of families' needs and the adequacy of parent-staff communication. It is our hope that the findings from the preliminary study reported here will stimulate further research in these important areas.

\section{ACKNOWLEDGMENTS}

This study was supported by American Cancer Society Institutional Research Grant No. IN-400Z and by NIH Biomedical Research Support Grant No. 019521-022989.

\section{REFERENCES}

Achenbach, T. M., \& Edelbrock, C. (1983). Manual for the child behavior checklist. Burlington, VT: Queen City Printers, Inc.

Brook, R. et al. (1979). Overview of the ten adult health status measures fielded in Rand's health insurance study. Medical Care, 17, supp.: entire volume.

Cassileth, B. R. et al. (1984). Psychosocial status in chronic illness. New England Journal of Medicine, 311, 506-511.

Cohen, J. (1977). Statistical power analysis for the behavioral sciences (Rev. ed.). New York: Academic Press.

Cohen, J., \& Cohen, P. (1983). Applied multiple regression/correlation analysis for the behavioral sciences (2nd Ed.). Hillsdale, NJ: Lawrence Erlbaum Associates.

Dirks, J., Paley, A., \& Fross, K. (1979). Panic-fear research in asthma and the nuclear conflict theory of asthma: Similarities, differences and clinical applications. British Journal of Medical Psychology, 52, 71-76.

Epstein, N., Baldwin, L., \& Bishop, D. (1983). The McMaster Family Assessment Device. Journal of Marital and Family Therapy, 9, 171-180.

Gortmaker, S. L. (1985). Demography of chronic childhood diseases. In Hobbs, N., \& Perrin, J. M. (Eds.). Issues in the care of children with chronic illness. San Francisco: Josey-Bass.

Hobbs, N., \& Perrin, J. M. (Eds.). (1985). Issues in the case of children with chronic illness. San Francisco: Jossey-Bass.

Hobbs, N., Perrin, J. M., \& Ireys, H. T. (1985). Chronically ill children and their families. San Francisco: Jossey-Bass.

Hutchins, V. (1984). Keynote Address. Proceeding of Conference on The Use of Case Mix Based Prospective Payment for Inpatient Pediatric Hospital Care. Sponsored by the National Association of Children's Hospitals and Related Institutions, Inc. and U.S. Department of Health and Human Services. Merrifield, VA: Cardinal Printing Co.

Meijer, A. (1979). Emotional disorders of asthmatic children. Child Psychiatry and Human Development, 9, 161-169.

Miller, I. W. et al. (1985). The McMaster Family Assessment Device: Reliability and validity. Journal of Marital and Family Therapy, 11, 345-356. 
Newacheck, P. W., Budetti, P. P., \& Halfon, N. (1986). Trends in activity-limiting chronic conditions among children. American Journal of Public Health, 76, 178-184.

Perrin, J. M., \& MacLean, W. E. (1988). Children with chronic illness: The prevention of dysfunction. The Pediatric Clinics of North America, 35, 1325-1337.

Pless, I. B. (1984). Clinical assessment: Physical and psychological functioning. In Symposium on Chronic Disease in Children, 32, 33-41.

Pless, I. B., \& Perrin, J. M. (1985). Issues common to a variety of illnesses. In Hobbs, N. and Perrin, J. M. (Eds.), Issues in the care of children with chronic illness. San Francisco: Jossey-Bass.

Poznanski, E. O. (1984). Children's depression rating scale-revised. Chicago: Youth Affective Disorders Clinic, University of Chicago Medical Center.

Poznanski, E. et al. (1979). A depression rating scale for children. Pediatrics, 65, 442-450.

Siegal, S. E. (1980). The current outlook for childhood cancer: The medical background. In Kellerman, J. (Ed.) Psychological aspects of childhood cancer. Springfield, IL: Charles C, Thomas.

Silverman, M. M., \& Koretz, D. S. (1989). Preventing mental health problems. In Stein, R. E. K. (Ed.), Caring for children with chronic illness: Issues and strategies. New York: Springer Publishing Company.

Starfield, B. (1985). Giant steps and baby steps: Toward child health. American Journal of Public Health, 75, 599-604.

Staudenmayer, H. (1985). Parental anxiety and other psychosocial factors associated with childhood asthma. Journal of Chronic Disease, 34, 627-632.

Stein, R. E. K., \& Jessop, D. J. (1982). A non-categorical approach to chronic childhood illness. Public Health Reports, 97, 354-362.

Stein, R. E. K., \& Jessop, D. J. (1984). General issues in the care of children with chronic physical conditions. Pediatric Clinics of North America, 31, 89-199.

Stein, R. E. K., \& Jessop, D. J. (1984). Relationship between health status and psychological adjustment among children with chronic conditions. Pediatrics, 73, 169-174.

Stein, R. E. K. (Ed.). (1989). Caring for children with chronic illness: Issues and strategies. New York: Springer Publishing Company. 